\title{
Exploration of the Problematic Twitter, Facebook Uses and Their Relationships with Psychopathological Symptoms Among Facebook
}

\section{Users}

\author{
Stéphanie Laconi ${ }^{1,}{ }^{,}$, Elodie Verseillié ${ }^{1}$ and Henri Chabrol ${ }^{1}$ \\ ${ }^{1}$ Centre d'Études et de Recherches en Psychopathologie et Psychologie de la Santé - CERPPS, EA7411, UFR de Psychologie, Université de Toulouse 2 Jean Jaurès, 5 Allées Antonio \\ Machado, 31058 Toulouse Cedex, France \\ "Corresponding author: Stéphanie Laconi, UFR de Psychologie, Université de Toulouse 2 Jean Jaurès, 5 Allées Antonio Machado, 31058 Toulouse Cedex, France. Tel: \\ +33-629441868, E-mail: stephanielaconi.b@gmail.com
}

Received 2016 October 09; Revised 2018 February 01; Accepted 2018 March 18.

\begin{abstract}
Background: Problematic Internet Use (PIU), as well as Problematic Facebook Use (PFU), is a growing concern worldwide. Like Facebook, Twitter is a widely used social networking site. Yet, no study has been conducted on the specific problematic Twitter use (PTU).

Objectives: The main goal of this study was to explore the rate of problematic Twitter and Facebook uses, their relationships and differences in terms of psychopathological and internet-related variables.

Patients and Methods: A sample of 822 Facebook users (55\% women) aged from 18 to 29 (Mean =21.6; SD = 2.8) completed a set of questionnaires assessing Twitter, Facebook, and the internet use characteristics and problematic uses, as well as psychopathological symptoms.

Results: Among the total sample, approximately 18\% of the participants had a PIU. Besides, more than $4 \%(n=34)$ had a PFU with a significantly higher rate of women $(P<0.01)$. Twitter users were represented by approximately $32 \%(n=259)$ of the sample. $21 \%(n=$ 55) reported a PIU, 3.1\% $(n=8)$ a PTU $(n=8)$, and 3.9\% $(n=10)$ a PFU with a significant majority of women $(P<0.05)$. Multiple-regression analysis revealed significant differences between PTU and PFU, particularly in terms of time spent on Facebook and psychopathological symptoms.

Conclusions: PFU was particularly related to depression and anxiety symptoms while PTU was not. Moreover, our results suggest further exploring the specificity of specific Social Networking Site (SNS) instead of encompassing them into a general problematic use of the internet or SNS. This exploratory study had limitations and needs to be completed by research focusing on relationships and differences between these uses. Future studies need to focus on the relationship between problematic SNS uses, taken separately, with psychopathology, and especially pathological personality traits, by taking gender into account.
\end{abstract}

Keywords: Social Networking, Psychopathology, Young Adult, Internet, Addictive Behavior

\section{Background}

Internet addiction or Problematic Internet Use (PIU) appeared two decades ago and has been defined as an inappropriate use causing a significant impact on the psychological, social, professional, or school functioning $(1,2)$. Even if PIU has not been consensually recognized yet, many studies revealed how similar PIU is to other clinical disorders, like pathological gambling and drug dependence. A significant number of PIU definitions and diagnostic criteria include symptoms of withdrawal or tolerance (3). For several years, many authors have argued PIU can be divided into two major categories: Generalized and specific problematic internet use (SPIU). The former includes a multidi- mensional use of the internet while the latter regroups all the specific activities that could be pursued online $(4,5)$.

Despite the benefits which can be related to it, using the internet for social motives and using social networking site (SNS) have been identified as potentially highly addictive $(6,7)$. Consequently, an increasing number of studies have been focused on the problematic SNS use in general or problematic Facebook use (PFU) in particular, with some criticisms about the lack of a consensus and different diagnostic criteria used. However, PFU appears as an addictive disorder, similar to PIU and other behavioral addictions (8, 9). Therefore, PFU has been defined as a "specific form of internet addiction" (10) with at least preoccupation, toler- 
ance, and mood modifications (9), leading to negative consequences on daily life (7).

Like other online addictive disorders, PFU tends to be more prevalent among young users (11). In recent studies among university students, PFU varies between $2 \%$ in Nigeria (12), $4 \%$ in Philippine (13), 5\% in Turkey (14), and up to $47 \%$ in Malaysia (11). In France, $4.5 \%$ of addicts among internet users (15) and 10\% among college and university students have been found (16). It consistently occurs more frequently among women $(6,10,16)$.

Little investigation has been conducted on other problematic SNS uses, or the focus has been on a general SNS problematic use while distinction seems necessary (17). The problematic use is rarely explored including for Twitter. Yet, one author suggested, "140 character is even more addictive" (140 characters' standard) (18). There is little study paying particular attention to the problematic Twitter use (PTU) (19). One recent study focused on the excessive use of Twitter among college students and revealed that time spent on Twitter was related to "Microblog excessive use" but they also found a relationship between this excessive use and loneliness (19). One Chinese study focused on Weibo (similar to Twitter) and revealed how addictive and problematic this SNS use could be (20).

As PIU, PFU appears to be related to psychopathological variables particularly depressive and anxiety symptoms, among college and university students $(7,15,16)$. Other studies showed PFU was highly correlated with other specific PIU among students and adults, social anxiety (17), insomnia (7), and low self-esteem among college students (21) or low life satisfaction among university students (22). Depressive symptoms seem to precede PFU (23) as shyness and loneliness $(24,25)$. However, no causal relationships have been established.

\section{Objectives}

Given the lack of empirical data, our aims were to explore the prevalence of PTU and PFU among a French sample of social networking sites users by taking gender into consideration, to examine differences between Twitter and non-Twitter users regarding internet and Twitter-related variables, and to explore differences between PFU and PTU predictors. Besides, the psychometric index of PFU and PTU scales was assessed.

\section{Patients and Methods}

\subsection{Participants and Procedure}

The final sample comprised 822 participants (Mean \pm $\mathrm{SD}=21.6 \pm 2.8$; age range 18 - 29; 55\% female, $\mathrm{n}=455)$.
The sample consisted of 572 students (70\%), 188 employees (23\%), and 62 inactive persons (7\%). The participants were recruited between January and March 2015 through Twitter and Facebook. Inclusion criteria included being aged between 18 and 30 years, having a Facebook account, and having completed all the scales. Among the population ( $\mathrm{N}$ =827), only five participants used Twitter but no Facebook, and they were excluded in order to retain a homogeneous sample of Facebook users. All participants were informed of the confidentiality and the anonymity of their responses and agreed to give their free and informed consent.

\subsection{Measures}

We assessed PIU using the problematic internet use questionnaire-9 (PIUQ; 28). Its nine items are rated on a 5point scale. The total score varies from nine to 45 . Participants scoring higher than or equal to 22 were considered problematic internet users. The PIUQ and its 9-item form presented good psychometric properties (26). Cronbach's alpha of the PIUQ-was 0.77 in our study.

PFU was assessed using the most used scale, the Bergen Facebook addiction scale (BFAS; 11). Since there was no French version of the scale, translations and backtranslations were performed by the authors. While originally constituted 18 items, the BFAS includes six items rated on a 5-point scale. Scores range from six to 30. As proposed by the authors and applied in a previous study, scoring three or above on at least four items suggests PFU (12). One validating study reported excellent Cronbach's alpha: $\alpha=0.91$ (27) as original authors: $\alpha=0.83$ (10).

Given the lack of an adapted scale, the BFAS was modified by replacing "Facebook" with "Twitter" (BFAS-T). This has already been done to assess "Facebook, Twitter, Instagram, and the like” instead of Facebook (28). Scores also range from five to 30 and a score of three or higher on at least four items suggested PTU. Concerning a previous study (29), two single self-diagnostic questions were also used to distinguish participants "self-perceived" as problematic Facebook and/or Twitter users. Answers were on a dichotomous format (yes/no). As in previous studies (30), the average time spent on the internet, Facebook, and Twitter was assessed by multiplying the approximate number of hours per day and days per week.

A French version of the brief symptom inventory (BSI; 33) was used to assess psychopathological symptoms. Each of the 53 items is rated on a 5-point scale. Higher scores suggest a higher psychological distress. The BSI has good psychometric properties with an excellent internal consistency: $\alpha=0.90$ (31) and $\alpha=0.96$ in our study. 


\subsection{Data Analysis}

Exploratory factorial analysis (EFA) with Varimax rotation was conducted on the BFAS and BFAS-T scales. The Bartlett test of sphericity and the criterion KMO (KaiserMeyer-Olkin) were also reported.

Convergent validity was explored for these two scales through associations with PIU and time spent on each SNS. Kappa values were also reported between the PFU and PTU scales and the two self-perceived problematic use items. Positive and negative predictive value (PPV and NPV) were calculated. Reliability was evaluated through Cronbach's alphas for all the scales.

The Chi-squared test was used to assess and compare the presence of PTU and PFU by gender. Independent samples t-test was performed to compare Twitter and nonTwitter users. The relationship between PFU, PTU, and other variables was assessed with correlational analyses (Pearson). To explore predictors of PTU and PFU, hierarchical regression analyses were performed. All analyses were conducted using SPSS 20.

\section{Results}

The BFAS achieved an excellent reliability, with a Cronbach's alpha of $\alpha=0.81$, as the BFAS-T with $\alpha=0.90$. The exploratory factor analysis of the two scales yielded one factor with an eigenvalue above one and factor loadings greater than 0.3. This factor explained $50 \%$ of the total variance of the BFAS and 70\% of the variance of the BFAS-T. The KMO was 0.86 for the BFAS and 0.90 for the BFAS-T, and the Bartlett tests were 1311.56 (15) and 1028.27 (15) ( $\mathrm{P}<0.001)$. Correlation analyses, introduced below, highlighted the convergent validity of the two scales. The mean agreement for PFU was $\kappa=0.22$ for the whole sample. The BFAS sensitivity, specificity, PPV, and NPV values were 0.82, 0.82, 0.16, and 0.99, respectively. The mean agreement for PTU among Twitter users was $\kappa=0.37$. Sensitivity, specificity, PPV, and NPV values were $0.73,0.93,0.27$, and 0.99, respectively.

Among our participants, 68.5\% $(n=563)$ had only Facebook (55\% women, $\mathrm{n}=312$ ). PFU was represented by 34 (4.1\%; $79.4 \%$ women, $\mathrm{n}=27, \mathrm{P}<0.01$ ). Among problematic Facebook users who owned a Twitter account $(n=10)$, only one had a PTU. PIU was represented by 147 (17.9\%) participants (54\% women, $\mathrm{n}=80$ ). Self-perceived PFU was represented by $20 \%(n=166)$ of users ( $55 \%$ women, $n=111, P=0.001)$.

Among 31.5\% of the participants who also had Twitter, $55 \%$ were women $(n=143)$. In this sample, $21 \%(n=55)$ had a PIU (64\% women, $n=35), 3.9 \%(n=10)$ a PFU (90\% women, $\mathrm{n}=9, \mathrm{P}=0.02)$, and 3.1\% $(\mathrm{n}=8)$ a PTU (75\% women, $\mathrm{n}=6)$. Among users with PTU, one also had a PFU and seven (87.5\%) also had a PIU (5 women). Self-perceived PTU was represented by $8.5 \%(n=22)$ of users ( 12 women). There were also
18.1\% ( $\mathrm{n}=47)$ with self-perceived PFU (55\% women, $\mathrm{n}=35, \mathrm{P}$ $=0.003)$.

In performing T-tests, Twitter users were compared with non-Twitter users in terms of internet-related and psychopathological variables. These results are detailed in Table 1 .

The results of correlation analysis are detailed in Tables 2 and 3, and those of regression analysis in Table 4. Only significantly correlated variables have been included.

\section{Discussion}

Despite the lack of validation studies of the BFAS and the novelty of the BFAS-T, our results suggested the good psychometric properties of the scales. Consistent with previous studies (10), the BFAS (as the BFAS-T) was a onedimensional measure of PFU. Similar to internal consistency, convergent validity was high in this sample. Besides, agreement analyses also raised the interest of our items on the self-perceived problematic use. Even if PPV was low (self-items found more problematic users than the scales), the other results were high and suggest these items could represent a quick and effective way to assess PFU and PTU. More investigations are required to deepen these interpretations but first, a consensual and criterion-referenced definition of these problematic uses is essential.

Our results showed that PFU was more frequent among women, in line with previous studies $(6,10,16)$. These results can be explained by the fact that SNS and communication activities, in general, are preferred by women, as the literature has shown (30). For Twitter, no significant gender differences were retrieved.

Mean comparison suggested that only time spent on the internet and PIU scores were significantly different between Twitter and non-Twitter users, with Twitter users spending almost three-fold more time online. This result highlights that specific SNS and problematic uses are not necessarily concurrent, at least for Twitter and Facebook. However, PIU and time spent on the internet were higher among Twitter users, which sounds like an evidence for the severity caused by the multiplicity of used SNS.

Finally, given the high correlation coefficients retrieved between PTU and time spent on Twitter, time spent on Twitter could emphasize the odds of having a PTU or having a PTU was associated with more time spent on Twitter as a symptom of tolerance. Higher scores of PTU could be also explained by less time spent on Facebook, maybe for the benefit of time on Twitter particularly. PTU was also predicted by the other internet-related variables, suggesting how PTU scores could reflect an excessive internet use or multiple specific PIU and how PTU is related 


\begin{tabular}{|c|c|c|c|c|}
\hline Variables & Twitter Users $(\mathbf{n}=259)^{\mathbf{b}}$ & Non-Twitter Users $(n=563)^{b}$ & $\mathbf{F}(\mathbf{d f})$ & t-test \\
\hline \multicolumn{5}{|l|}{ Internet-related } \\
\hline Problematic internet use & $17.9 \pm 4.4$ & $17.1 \pm 4.3$ & $0.038(496.6)$ & $2.56^{*}$ \\
\hline Problematic Facebook use & $8.7 \pm 3.3$ & $8.5 \pm 3.4$ & $0.003(820)$ & 0.62 \\
\hline Problematic Twitter use & $7.3 \pm 3.2$ & - & - & - \\
\hline Time on Facebook & $14.5 \pm 14.3$ & $12.4 \pm 15.1$ & $2.329(820)$ & 1.90 \\
\hline Time on Twitter & $8.8 \pm 11.4$ & - & - & - \\
\hline \multicolumn{5}{|l|}{ Psychopathological } \\
\hline Somatization & $3.3 \pm 4.4$ & $2.9 \pm 4.1$ & $2.212(820)$ & 1.28 \\
\hline Obsessive-compulsive & $5.7 \pm 4.8$ & $5.3 \pm 4.6$ & $0.227(820)$ & 1.23 \\
\hline Interpersonal sensitivity & $3.3 \pm 3.6$ & $3.0 \pm 3.2$ & $4.988(819)$ & 1.04 \\
\hline Anxiety & $4.0 \pm 4.5$ & $3.7 \pm 4.2$ & $0.949(818)$ & .84 \\
\hline Hostility & $3.1 \pm 3.5$ & $3.2 \pm 3.3$ & $0.020(820)$ & -0.30 \\
\hline Phobic anxiety & $2.5 \pm 3.6$ & $2.1 \pm 3.0$ & $5.308(820)$ & 1.44 \\
\hline Paranoid ideation & $4.7 \pm 4.0$ & $4.2 \pm 3.7$ & $0.903(820)$ & 1.70 \\
\hline Psychoticism & $3.3 \pm 3.6$ & $2.9 \pm 3.2$ & $4.091(819)$ & 1.50 \\
\hline
\end{tabular}

Abbreviations: df, degree of freedom; F, F statistics; M, Mean scores; SD, standard deviation

${ }^{a}$ T-test, T statistics: ${ }^{* * *} \mathrm{P}<0.001 ;{ }^{* *} \mathrm{P}<0.01{ }^{*} \mathrm{P}<0.05$.

${ }^{\mathrm{b}}$ Values are expressed as Mean $\pm \mathrm{SD}$.

Table 2. Correlation Analysis Between Internet-Related Variables and Psychopathology Among Facebook Users $(\mathrm{n}=822)^{\mathrm{a}}$

\begin{tabular}{|c|c|c|c|c|c|}
\hline & Time on the Internet & Time on Facebook & PIU & PFU & BSI \\
\hline Time on the internet & - & $0.42^{* *}$ & $0.26^{* *}$ & 0.05 & $0.10^{* *}$ \\
\hline Time on Facebook & & - & $0.27^{* *}$ & $0.37^{* *}$ & $0.18^{* *}$ \\
\hline PIU & & & - & $0.53^{* *}$ & $0.44^{* *}$ \\
\hline PFU & & & & - & $0.36^{* *}$ \\
\hline BSI & & & & & - \\
\hline
\end{tabular}

Abbreviations: BSI, brief symptom inventory; PFU, problematic Facebook use; PIU, problematic internet use; PFU, problematic Facebook use.

$\mathrm{a}^{* *} \mathrm{P}<0.01$

\begin{tabular}{|c|c|c|c|c|c|c|c|}
\hline & Time on the Internet & Time on Facebook & Time on Twitter & PIU & PFU & PTU & BSI \\
\hline Time on the internet & - & $0.32^{* *}$ & $0.16^{* *}$ & $0.18^{* *}$ & -0.02 & 0.04 & 0.08 \\
\hline Time on Facebook & & - & 0.04 & $0.20^{* *}$ & $.33^{* *}$ & -0.07 & $0.18^{* *}$ \\
\hline Time on Twitter & & & - & $0.16^{* *}$ & -0.04 & $0.54^{* *}$ & 0.12 \\
\hline PIU & & & & - & $0.47^{* *}$ & $0.34^{* *}$ & $43^{* *}$ \\
\hline PFU & & & & & - & $0.18^{* *}$ & $0.33^{* *}$ \\
\hline PTU & & & & & & - & $0.22^{* *}$ \\
\hline
\end{tabular}

Abbreviations: BSI, brief symptom inventory; PFU, problematic Facebook use; PIU, problematic internet use; PTU, problematic Twitter use.

${ }_{\mathrm{a}^{* *}} \mathrm{P}<0.01$

to time spent online. Finally, in this study, PIU scores appeared to play a significant role in PFU scores. Previous studies showed a particular relationship between PIU and PFU where Facebook use contributed to the severity of PIU (32). Time spent on the internet and Facebook was a positive predictor of PFU (33) whereas time spent on Twitter was negative. This result highlights the singularity of time spent on Facebook and Twitter. However, given the overlap between problematic uses, these conclusions need substantiation.

All psychopathological symptoms were related to PTU and PFU scores but a few results were significant in regression analyses, probably due to the high rates of multiple problematic users and the high influence of internet- 


\begin{tabular}{|c|c|c|c|c|c|c|c|}
\hline \multirow[t]{2}{*}{ Steps } & & \multicolumn{3}{|c|}{$\operatorname{PFU}(\mathbf{n}=\mathbf{8 2 2})$} & \multicolumn{3}{|c|}{ PTU $(\mathbf{n}=\mathbf{2 5 9})$} \\
\hline & & $\beta$ & $F(d f)$ & $\Delta \mathbf{R}^{2}$ & $\beta$ & $F(\mathbf{d f})$ & $\Delta \mathbf{R}^{2}$ \\
\hline \multirow[t]{4}{*}{ Step 1} & & & $40.86(3)$ & $0.12^{* * *}$ & & $30.94(3)$ & $0.26^{* * *}$ \\
\hline & Time on Facebook & $0.34^{* * *}$ & - & - & $-0.17^{* *}$ & - & - \\
\hline & PFU & - & - & - & $0.26^{* * *}$ & - & - \\
\hline & PTU & $0.23^{* * *}$ & - & - & - & - & - \\
\hline \multirow[t]{13}{*}{ Step 2} & & - & $11.10(9)$ & $0.21^{* * *}$ & - & $1.14(9)$ & 0.26 \\
\hline & Time on Facebook & $0.29^{* * *}$ & & & $-0.17^{* *}$ & & \\
\hline & Time on Twitter & $0.13^{*}$ & & & $0.45^{* * *}$ & & \\
\hline & PTU & $0.13^{*}$ & & & - & & \\
\hline & Somatization & 0.03 & - & - & 0.04 & - & - \\
\hline & Obsessive-compulsive & $0.11^{*}$ & - & - & 0.05 & - & - \\
\hline & Interpersonal sensitivity & 0.01 & - & - & 0.09 & - & - \\
\hline & Depression & -0.06 & - & - & -0.11 & - & - \\
\hline & Anxiety & 0.08 & - & - & 0.01 & - & - \\
\hline & Hostility & $0.08^{*}$ & - & - & -0.02 & - & - \\
\hline & Phobic anxiety & -0.01 & - & - & -0.05 & - & - \\
\hline & Paranoid ideation & 0.09 & - & - & 0.04 & - & - \\
\hline & Psychoticism & 0.02 & - & - & 0.12 & - & - \\
\hline
\end{tabular}

Abbreviations: PFU, problematic Facebook use; PTU, problematic Twitter use; df, degree of freedom.

${ }^{a} \beta$, standardized beta; $\mathrm{F}, \mathrm{F}$ statistics; $\Delta \mathrm{R}^{2}$, change in variance.

$\mathrm{b}^{*} \mathrm{p}<0.05 ;{ }^{* *} \mathrm{P}<0.01 ;{ }^{* * * *} \mathrm{P}<0.001$.

related variables. Obsessive-compulsive symptoms played a significant role in PFU scores, suggesting that PFU is similar to obsessive-compulsive disorders more than to addictive disorders. Moreover, hostility seems also to predict PFU, which can be explained by the anonymity in SNS in general. Contrarily to PFU, PTU was not explained by psychopathological variables but it could be related to the small proportion of problematic Twitter users. However, these results showed the differences between Facebook and Twitter users and emphasized the importance of the specific exploration of each SNS.

Some limitations can be highlighted such as sample size and characteristics. Critics can be raised against the methodology (cross-sectional design, assessment tools). Problematic Twitter and Facebook users, as other internet users, are surely frequently involved in other online specific activities (30), which is an obstacle to the understanding of the particular relationship between problematic uses and psychopathological symptoms.

With an increasing number of SNS users, it seems important to improve our understanding of characteristics and differences between each and several SNS uses. It also appears essential to properly evaluate PFU and PIU in accordance with the strong theoretical background. The lack of available data increases the pertinence of this research, which highlighted the presence of problematic Facebook and Twitter use among French users.

\section{Footnotes}

Authors' Contribution: Elodie Verseillié and Stéphanie Laconi designed the study, made statistical analysis, and drafted the manuscript; Henri Chabrol provided significant input in study design and re-drafting. All authors read and approved the final manuscript.

Conflict of Interests: The authors declare no conflict of interest.

Funding/Support: No financial support was received for this study. 


\section{References}

1. Beard KW, Wolf EM. Modification in the proposed diagnostic criteria for Internet addiction. Cyberpsychol Behav. 2001;4(3):377-83. doi: 10.1089/109493101300210286. [PubMed: 11710263].

2. Spada MM. An overview of problematic Internet use. Addictive Behaviors. 2014;39(1):3-6. doi: 10.1016/j.addbeh.2013.09.007.

3. Laconi S. Addiction à Internet: Définitions et évaluations [Internet addiction : Definitions and assessments]. Saarbrücken: Presses Académiques Francophones; 2015. French.

4. Davis RA. A cognitive-behavioral model of pathological Internet use. Comput Hum Behav. 2001;17(2):187-95. doi: 10.1016/s07475632(00)00041-8.

5. Montag C, Bey K, Sha P, Li M, Chen YF, Liu WY, et al. Is it meaningful to distinguish between generalized and specific Internet addiction? Evidence from a cross-cultural study from Germany, Sweden, Taiwan and China. Asia Pac Psychiatry. 2015;7(1):20-6. doi: 10.1111/appy.12122. [PubMed: 24616402].

6. Griffiths MD, Kuss DJ, Demetrovics Z. Social networking addiction: An overview of preliminary findings. Behavioral addictions. Elsevier; 2014. p. 119-41.

7. Koc M, Gulyagci S. Facebook addiction among Turkish college students: the role of psychological health, demographic, and usage characteristics. Cyberpsychol Behav Soc Netw. 2013;16(4):279-84. doi: 10.1089/cyber.2012.0249. [PubMed: 23286695].

8. Echeburua E. [Addiction to new technologies and to online social networking in young people: A new challenge]. Adicciones. 2010;22(2):915. French. [PubMed: 20549142].

9. Kuss DJ, Griffiths MD. Online social networking and addiction-a review of the psychological literature. Int J Environ Res Public Health. 2011;8(9):3528-52. doi: 10.3390/ijerph8093528. [PubMed: 22016701]. [PubMed Central: PMC3194102].

10. Andreassen CS, Torsheim T, Brunborg GS, Pallesen S. Development of a Facebook Addiction Scale. Psychol Rep. 2012;110(2):501-17. doi: 10.2466/02.09.18.PR0.110.2.501-517. [PubMed: 22662404].

11. Jafarkarimi H, Sim ATH, Saadatdoost R, Hee JM. Facebook Addiction among Malaysian Students. Int J Inf And Edu Tech. 2016;6(6):465-9. doi: 10.7763/ijiet.2016.v6.733.

12. Alabi OF. A survey of Facebook addiction level among selected Nigerian University undergraduates. New Media Mass Commun. 2013;10(2012):70-80.

13. Marcial DE. Are you a Facebook addict? Measuring Facebook addiction in the Philippine University. Int Proc Econ Dev Res. 2013;66:12-5.

14. BALCI Ş, Gölcü A. Facebook Addiction among University Students in Turkey:" Selcuk University Example". Selçuk Üniversitesi Türkiyat Araștırmaları Dergisi. 2013;1(34):255-78.

15. Couderc E. Recherche d'une addiction aux réseaux sociaux et étude du profil d'utilisateur concerné [Exploration of an addiction to social networking and study of the profile of connected user]. Université de Limoges. 2012. French.

16. Moreau A, Laconi S, Delfour M, Chabrol H. Psychopathological profiles of adolescent and young adult problematic Facebook users. Comput Hum Behav. 2015;44:64-9. doi: 10.1016|j.chb.2014.11.045.

17. Lee-Won RJ, Herzog L, Park SG. Hooked on Facebook: The Role of Social Anxiety and Need for Social Assurance in Problematic Use of Facebook. Cyberpsychol Behav Soc Netw. 2015;18(10):567-74. doi: 10.1089/cyber.2015.0002. [PubMed: 26383178].

18. Weinschenk S. Why we're all addicted to texts, Twitter and Google. Dopamine makes you addicted to seeking information in an endless loop. PsychologyToday; 2012. Available from: https: //www.psychologytoday.com/intl/blog/brain-wise/201209/whywere-all-addicted-texts-twitter-and-google.

19. Ndasauka Y, Hou J, Wang Y, Yang L, Yang Z, Ye Z, et al. Excessive use of Twitter among college students in the UK: Validation of the Microblog Excessive Use Scale and relationship to social interaction and loneliness. Comput Hum Behav. 2016;55:963-71. doi: 10.1016/j.chb.2015.10.020.

20. Miles PC, Zhang LG. China turns to Tweeting: Exploring the problematic use of Tweeting in China. Int J Business And Soc Sci. 2012;3(2):91-4.

21. Herrera Harfuch MF, Pacheco Murguía MP, Palomar Lever J, Zavala Andrade D. La adicción a Facebook relacionada con la baja autoestima, la depresión y la falta de habilidades sociales [Facebook addiction related to low self-esteem, depression and lack of social skills]. Psicología Iberoamericana. 2010;18(1). French.

22. Satici SA, Uysal R. Well-being and problematic Facebook use. Comput Hum Behav. 2015;49:185-90. doi: 10.1016/j.chb.2015.03.005.

23. Hong FY, Huang DH, Lin HY, Chiu SL. Analysis of the psychological traits, Facebook usage, and Facebook addiction model of Taiwanese university students. Telemat Informat. 2014;31(4):597-606. doi: 10.1016/j.tele.2014.01.001.

24. Omar B, Subramanian K. Addicted to Facebook: Examining the roles of personality characteristics, gratifications sought and Facebook exposure among youths. Gstf J On Media Commun. 2013;1(1). doi: 10.5176/2335-6618_1.1.6.

25. Shettar M, Karkal R, Kakunje A, Mendonsa RD, Chandran VM. Facebook addiction and loneliness in the post-graduate students of a university in southern India. Int J Soc Psychiatry. 2017;63(4):325-9. doi: 10.1177/0020764017705895. [PubMed: 28504040].

26. Laconi S, Rodgers RF, Chabrol $\mathrm{H}$. The measurement of Internet addiction: A critical review of existing scales and their psychometric properties. Comput Hum Behav. 2014;41:190-202. doi: 10.1016/j.chb.2014.09.026.

27. Phanasathit M, Manwong M, Hanprathet N, Khumsri J, Yingyeun R. Validation of the Thai version of Bergen Facebook addiction scale (Thai-BFAS). J Med Assoc Thai. 2015;98 Suppl 2:S108-17. [PubMed: 26211112].

28. Schou Andreassen C, Billieux J, Griffiths MD, Kuss DJ, Demetrovics $\mathrm{Z}$, Mazzoni E, et al. The relationship between addictive use of social media and video games and symptoms of psychiatric disorders: A large-scale cross-sectional study. Psychol Addict Behav. 2016;30(2):25262. doi: 10.1037/adb0000160. [PubMed: 26999354].

29. King DL, Delfabbro PH, Griffiths MD. Trajectories of problem video gaming among adult regular gamers: an 18-month longitudinal study. Cyberpsychol Behav Soc Netw. 2013;16(1):72-6. doi: 10.1089/cyber.2012.0062. [PubMed: 23098213]

30. Laconi S, Tricard N, Chabrol H. Differences between specific and generalized problematic Internet uses according to gender, age, time spent online and psychopathological symptoms. Comput Hum Behav 2015;48:236-44. doi: 10.1016/j.chb.2015.02.006.

31. ANQ. [National quality measures of results in stationary psychiatry]. Brief Symptom Checklist [database on the Internet]; 2012. Available from: http://www.anq.ch/fileadmin/redaktion/francais/120611_ InfoInstrument_BSCL_FR_v2.pdf.

32. Kittinger R, Correia CJ, Irons JG. Relationship between Facebook use and problematic Internet use among college students. Cyberpsychol Behav Soc Netw. 2012;15(6):324-7. doi: 10.1089/cyber.2010.0410. [PubMed: 22703039].

33. Kirik AM, Arslan A, Çetinkaya A, Mehmet G. A quantitative research on the level of social media addiction among young people in Turkey. Int J Scs Cult Sport. 2015;3(3):108-22. 